\title{
TRIZ Analysis and Application for Innovation in Semiconductor Packaging Wire Bonding Process
}

\section{반도체 Packaging 와이어 본딩 공정 혁신을 위한 트리즈 분석과 활용}

\author{
Kwangjun Lee ${ }^{1}$, Yongwon Song ${ }^{2}$, Hongkyun Shim ${ }^{3}$, Sangook Jun ${ }^{4}$ \\ 이광준 ${ }^{1}$, 송용원 ${ }^{2}$, 심홍균 ${ }^{3}$, 전상욱 ${ }^{4}$ \\ ${ }^{1}$ Engineer, SK Hynix semiconductor Co., Ltd, South Korea, kwangjun.lee@sk.com \\ ${ }^{2}$ Professor, Dept. Nano \& Semiconductor Engineering, Korea Polytechnic University, South Korea, \\ ywsong@kpu.ac.kr \\ ${ }^{3}$ Engineer, SK Hynix semiconductor Co., Ltd, South Korea, hongkyun.shim@sk.com \\ ${ }^{4}$ Engineer, SK Hynix semiconductor Co., Ltd, South Korea, sangook.jun@sk.com
}

Corresponding author: Yong Won Song

\begin{abstract}
Since the 4th industrial revolution has progressed, all technologies in the world are continuously developing. Among them, the semiconductor industry is an ultra-high-density technology, and efforts are being made to develop high-quality products. The purpose of this paper is to investigate how to improve the technology of package process wire bonding. By introducing TRIZ specialized in problem-solving methods, the problem of the inner angle of the capillary was checked, and the correlation between the coupling force according to the change of the inner angle was analyzed in this line. As an analysis technique, micro-analysis was performed using a small human model, and a technical contradiction was defined based on this. Contradiction between two situations, the contradiction between two situations based on a solution model applying the matrix of 40 invention principles, the property to be improved is the speed, the property to be improved is the area of the moving object, and the solution is a flexible film/thin film It was to reduce friction. It was found that the increase in the internal angle reduced the stress of the ball neck (spherical neck), and it was confirmed that an increase in the internal angle above a certain level could induce stress in other aspects. The result of this paper is to confirm the improvement of adhesive strength by changing the capillary design, which is a subsidiary material.
\end{abstract}

Keywords: Wire Bond, TRIZ, Capillary Design, Inner Angle, BST, BPT

요약: 4차 산업혁명이 진행된 이후 세상의 모든 기술은 발전을 거듭하고 있다. 그중 반도체 산업은 초고밀도 기술이며 고 품질의 제품을 개발하기 위한 노력을 진행하고 있다. 본 논문에서는 Package(패키지) 공정 와이어본딩의 기술을 향상시키는 방법을 조사하는 것을 목적으로 한다. 문제 해결 방법에 특화된 TRIZ(트리즈)를 도입하여 캐필러리 내부 각도의 문제점에 관해서 확인하으며, 이 선에서 Inner Angle(내부 각도)의 변화에 따른 결합력의 상관관계를 분석하였다. 분석 기법으로는 작은 사람 모델을 활용하여 마이크로 한 분석을 하고, 이를 토대로 기술모순을 정의하였다. 두 가지 상황이

Received: March 16, 2021; 1st Review Result: May 01, 2021; 2nd Review Result: June 17, 2021

Accepted: July 31, 2021 
상충하는 모순 40 가지 발명 원리의 매트릭스를 적용한 솔루션 모델을 기반으로 한 두 상황 사이의 모순, 개선해야 할 특성은 속도, 악화되는 특성은 움직이는 물체의 면적, 해결책은 유연한 필름/박막으로 마찰을 줄이는 것이었습니다. 내부 각도의 증가가 Ball $\operatorname{Neck}$ (구형의 목)의 $\operatorname{Stress(ㅅㅡㅌㅡㄹㅔㅅㅡ)ㄹㅡㄹ~ㄱㅏㅁㅅㅗ~ㅅㅣㅋㅕ~ㅈㅜㅇㅓㅆㅇㅡㅁㅇㅡㄹ~ㅇㅏㄹ~ㅅㅜ~ㅇㅣㅆㅇㅓㅆㅇㅡㅁㅕ,~ㅇㅣㄹㅈㅓㅇ~ㅇㅣㅅㅏㅇㅇㅢ~}$ 내부 각도의 증가는 다른 측면에서의 Stress를 유발할 수 있음을 확인하였다. 본 논문의 결과는 부자재인 모세관 디자인을 변경하여 접착 강도의 향상을 확인하기 위한 것입니다.

핵심어: 와이어 본드, 트리즈, 캐필러리 디자인, 내부 각도, 볼 접합력 평가, 본드 접합력 평가

\section{1. 서론}

기술이 발전함에 따라서 반도체에 대한 부분도 직접 도가 매우 높아지고 있다. 특히 COVID-19로 인한 전 세계적인 범유행 현상으로 인하여 서버 형태의 반도체 수요가 증가 함에 따라서 제품의 고도화가 이루어지고 있으며, 반도체의 고도화[1]에 따른 반도체 품 질의 향상 역시 매우 중요한 기준으로 자리 잡고 있다. 반도체의 제조는 크게 Wafer 제 조, 산화, 포토, 식각, 증착 및 이온 주입, 금속 배선, Electrical die Sorting(EDS), Packaging 등 크게 8대 공정으로 구분된다[2]. 본 논문은 8대 공정 중 Packag 공정의 와이어 본[3] 공정 에서의 생산성 향상을 위하여 TRIZ를 통한 캐필러리 Design 변경을 진행하였으며 이를 기반으로 내부 각도의 변경에 따른 접착력 개선을 통한 생산성 향상에 대한 연구사례이 다.

\section{1 와이어 본딩(Wire Bonding)}

반도체 전(前) 공정을 마친 웨이퍼에는 장당 수백 수천 개의 칩(다이, Die)이 생산된다. 각각의 칩을 필요한 분야에 활용하기 위해서는 개별 칩으로 나누는 공정을 진행한 뒤, 전자가 흐르도록 외부와 도선을 연결한다. 이때 전기적 신호의 통로인 도선을 연결하는 방식이 바로 와이어 본딩이다. 와이어 본딩은 얇은 골드 와이어(Gold Wire)를 패드에 접합 시켜 내부의 칩과 외부를 연결하는 기술로서, 구조적 측면의 골드 와이어는 칩의 본딩 패드(1차 본딩)와 캐리어의 패드(2차 본딩)를 연결하는 다리 역할을 하는 것이다. 초창기 에는 리드 프레임(Lead Frame)을 사용했으나, 기술이 발전함에 따라 현재는 $\mathrm{PCB}$ (기판)를 주로 사용하고 있다. 서로 위치적으로 떨어져 있는 2 개의 패드를 연결하는 와이어 본딩 은 골드 와이어의 재질과 본딩 조건, 접합 위치(칩과 기판 사이 이외에도 칩과 칩 사이 혹은 기판과 기판 사이를 연결하기도 함) 등이 매우 다양하다.

와이어 본딩을 진행하는 데 있어 가장 핵심적인 장치는 캐필러리(Capillary)로, 이를 이용 할 땐 주로 골드 와이어를 적용한다. 골드 와이어는 전류의 흐름이 좋고 화학적으로 안 정되어 부식에 강하다. 또한 골드 와이어는 경도가 적당하여 1 차 본딩 시 볼이 잘 형성 되며, 2 차 본딩 시 반원 형태의 루프(Loop, 1차 본딩에서 2차 본딩까지의 와이어 모양)가 알맞게 형성된다[Fig. 1]. 


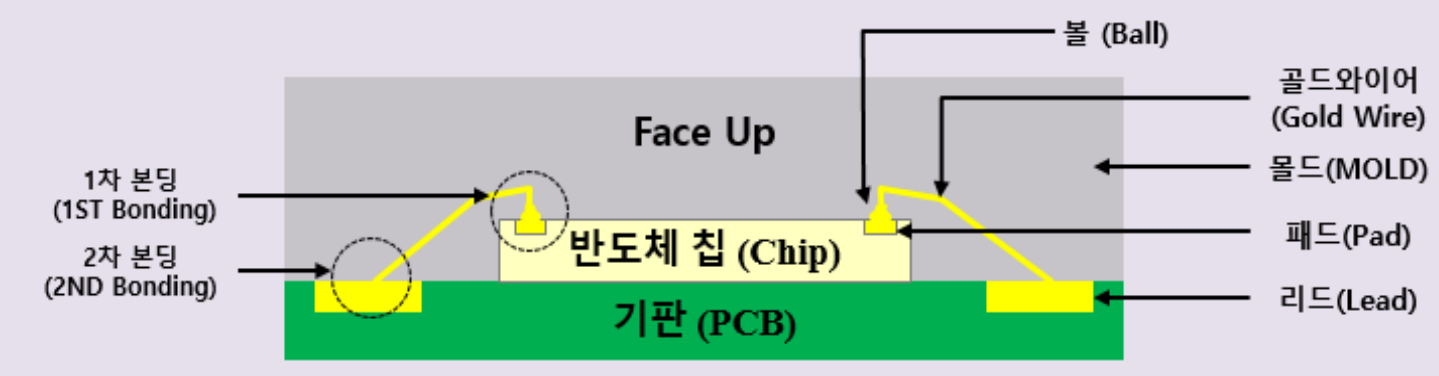

[그림 1] 와이어본딩 방법

[Fig. 1] Wire Bonding Process

반도체 공정에서 일반적으로 가장 많이 사용하는 방식은 열 압착 방식과 초음파 방식 의 장점을 합친 열초음파(Thermersonic) 방식으로 캐필러리에 열과 압력, 초음파를 가하여 가장 최적의 조건으로 Bonding이 된다. Packaging 공정은 골드와이어를 사용한 열 초음파 방식을 주로 사용한다. 와이어 본딩 공정에서 Bonding을 위해서는 캐필러리를 통하여 접 합을 진행하게 되는데 여기서 사용되는 제일 중요한 부자재인 캐필러리에 따라서 접착 면적, 접착 강도의 차이가 발생되게 된다. 이 접합력 향상은 BPT(Bond Pull Test)[4], BST(Bond Share Test)[5]를 통하여 수치화 할 수 있다. 해당 값들은 실제 접착된 골드 와이 어의 접착 강도와 인장 강도로 표현되며, 캐필러리가 궤적을 형성함에 따라 따라서 캐필 러리와 골드 와이어의 간섭에 의한 내부 마찰 발생으로 $\mathrm{BPT}$ 저하가 발생하게 된다. 이 에 대한 개선이 필요하며, BPT/BST는 신뢰할 수 있는 수준의 Data 확보가 필요하다.

\subsection{TRIZ (Teoriya Reshniya Izobretatelskikh Zadatch)}

창의적 문제해결 이론으로 알려진 트리즈(Theory of Inventive Problem Solving, TRIZ)는 러시아의 겐리히 알츠슐러(Genrich Altshuller)라는 발명가가 러시아 특허청에 등록된 약 100 만여 건의 특허를 분석하여 수준에 따라 5단계로 나누고, 높은 3-5 수준의 문제를 어떻게 해결하였는지 분석하여 문제해결의 공통 원리를 추출하여 만든 이론이다[6][7]. TRIZ는 문제 해결에 있어서 체계적인 접근 방법과 함께 문제 해결 Solution을 과학적이며 논리적으로 도출하도록 도와주는 이론으로 본 논문에서는 여러 TRIZ의 문제 분석 도구 중 기능 분석 및 인과 관계 분석을 이용하였다. 또한 문제 정의 및 해결을 위하여 모순 정립을 통한 40 가지 발명원리, 분리 원리, 물질-장 문제 모델 및 표준해를 사용하였다. 그리고 기능 분석을 이용해 문제 해결을 진행하였으며, IFR/모순/표준해를 통한 최종 아이디어를 도출하였다.

\section{2. 와이어본딩 품질 검증}

\section{1 품질 검증}

기판과 반도체 웨이퍼의 패드의 골드 와이어의 결속력을 확인하기 위해서는 다음과 같은 두 가지 방법으로 접합력(Bond Ability)을 확인한다. 첫 번째 Bond의 접합력을 
확인하기 위하여 BST(Ball Shear Test)를 진행한다. 해당 내용은 반도체의 패드와 골드 와이어의 접착력을 확인하기 위하여 첫 번째 Bonding 이후 금속 재질의 골드 와이어를 밀어내기 위한 특정 TIP을 이용하여 접합이 완료된 골드 와이어를 밀어내어 형성된 Grams를 측정하게 되어 있다[Fig. 2].

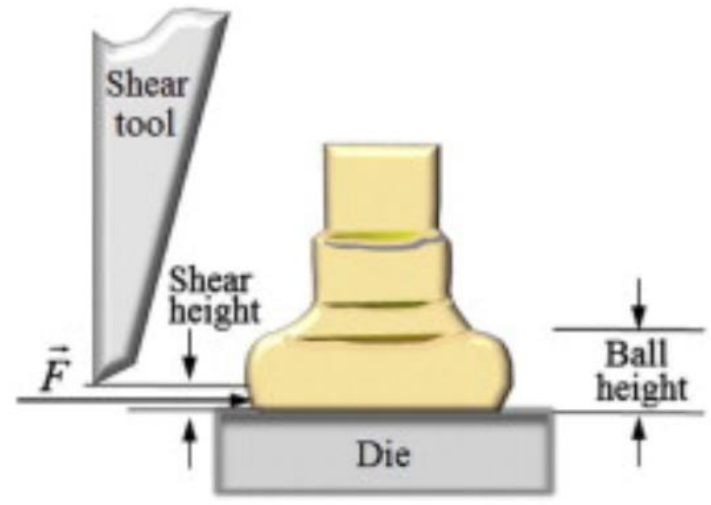

[그림 2] 볼 접합력 평가 기준

[Fig. 2] Ball Shear Test Standard

BST에 영향을 미치는 요인은 다음과 같으며[Table 1] 해당 Test에서도 Break Position 특정 Mode에 따라서 접합력(Grams)과 관계없이 불량으로 확인하고 있다. 해당 내용은 $\mathrm{BST}$ 를 측정한 이후 Mode와 형태에 따라서 접합된 접합력에 어떠한 영향을 미치고 있는지 확인하는 데 있어 참고해야 할 주요 항목이다.

[표 1] 볼 접합력 테스트 방법

[Table 1] Ball Shear Test Mode

\begin{tabular}{|c|c|}
\hline Mode & Break position \\
\hline 1 & Ball이 Band pad로부터 완전히 떨어지는 양상. 잔류 되는 Fold ball이 Bond pad에 없음 \\
\hline 2 & Ball 중간이 잘리면서 Ball shear 되는 경우 \\
\hline 3 & Ball이 Pad와 함께 떨어져 나오는 경우 \\
\hline 4 & Oxide damage나 Silicon damage가 발생하는 경우 \\
\hline
\end{tabular}

두 번째 Bonding의 접합력을 확인하기 위하여 BPT(Bond Pull Test)를 진행한다. BPT는 두 번째 Bonding의 접합력을 결정하는 방법으로 사용된다. Pull Strength 값은 보통 Grams로 표시되며, 일반적으로 Bonding 된 Wire의 Loop 최고점에서 Hook 형태의 고리를 사용하여 골드 와이어를 당기고 그 값을 결정한다[Fig.3]. 


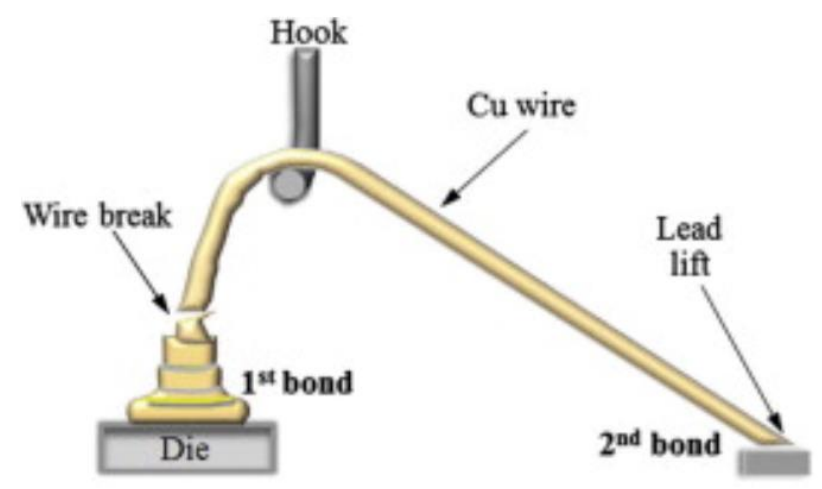

[그림 3] 본드 접합력 평가 기준

[Fig. 3] Bond Pull Test Standard

현재 사용되는 BPT의 기본적인 규정은 아래와 같으며, 해당 파단 Mode에 따라서 합격과 불합격으로 구분하여 제품에 대한 신뢰도를 구축하고 있다. 특히 특정 Mode에서는 접합력(Grams)과 관계없이 불량으로 확인하고 있다[Table 2]

[표 2] 본드 접합력 테스트 방법

[Table 2] Bond Pull Test Mode

\begin{tabular}{|c|c|}
\hline Mode & Break position \\
\hline 1 & Ball beck 부분이 끓어지는 경우 \\
\hline 2 & Stitch neck 부분이 끓어진 경우 \\
\hline 3 & Bond Pad로부터 Ball이 완전히 떨어질 경우 \\
\hline 4 & 2nd bond가 완전히 떨어질 경우 \\
\hline 5 & Bond neck 부분이 아닌 Loop 중간에서 끓어질 경우 \\
\hline 6 & Bond pad metal이 들뜨는 경우 \\
\hline 7 & Bond post에서 Plating 된 부분이 들뜨는 경우 \\
\hline
\end{tabular}

와이어 본딩 공정에서의 주요 기능에 대한 내용과 주요 Parameter에 대해서 아래와 같이 규정하고 있다. 주요 기능으로 표현된 내용에 대해서 세부적인 항목들은 다음과 같다[Table 3].

[표 3] 주요기능 구성요소 분석

[Table 3] Analysis of Major Functional Components

\begin{tabular}{|c|c|}
\hline Mode & Break position \\
\hline 본드 하중 & 표면에 작용하는 힘(압력) \\
\hline 본드 초음파 & 초음파(Ultrasonic Generator) \\
\hline 본드 시간 & 압력 초음파가 가해지는 시간 \\
\hline 루프 궤적 & 장비에서 캐필러리를 이용하여 금선의 높이를 만드는 이동경로 \\
\hline 캐필러리 & 매우 얇은 골드와이어를 접합 또는 결속시키기 위한 바늘과 콘 모양으로 루비 또는 \\
\hline 골드 와이어 & $18 \mu \mathrm{m}$ 의 머리카락보다 얇은 골드와이어로 겅 흠 함유량이 $99.99 \%$ 의 매우 높은 순도를 사용 \\
\hline
\end{tabular}




\begin{tabular}{|c|c|}
\hline 와이어 클램프 & 골드와이어를 잡아주거나 결속이 완료된 골드와이어를 끊어 냄 \\
\hline 히터 블럭 & 기판을 고정하여 열을 전달하는 기구 \\
\hline $\begin{array}{c}1 \text { 1st 본드 } \\
\text { (반도체 칩 결속) }\end{array}$ & 본드하중 / 본드초음파 / 본드시간 동안 금선을 칩에 접합하는 과정 \\
\hline $\begin{array}{l}\text { 2nd 본드 } \\
\text { (기판 결속) }\end{array}$ & 본드하중 / 본드초음파 / 본드시간 동안 금선을 리드에 접합하는 과정 \\
\hline
\end{tabular}

\section{2 규제 및 제약조건}

현재 조건에서의 변경점은 접합력의 저하가 발생하지 않도록 개선되어야 한다. 캐필러리의 주요 조건이 변경되는 경우 접합력이 상당량 변하는 조건에 대해서는 회사 내부 지침에 따라서 변경된 변경 점은 고정형태를 유지하도록 설계를 진행하였다. 단, Inner Angle의 변경과 관련해서는 골드와이어의 정상적인 형태를 유지할 수 있어야 하며 추가적인 개선과 관련해서는 현재 사용되는 $\mathrm{BPT}, \mathrm{BST}$ 의 기본적인 규정을 준수하면서 접합력이 개선되는 방향으로 진행하는 것을 원칙으로 검증하였다. 설비의 모든 arameter는 고정으로 운영 평가를 위한 모든 Data의 정합성을 확인하기 위하여 고정 설비에서만 평가하여 검증하도록 제약하였다.

\section{TRIZ를 사용한 문제분석}

\section{1 시스템 기능분석}

문제에 대한 세밀한 분석을 위해 TRIZ의 System 기능 분석을 진행하였다. System 기능 분석은 시스템 구성요소 분석 이후 관련 부품들의 상호 연관 관계 분석을 통하여 더욱 정확하고 빠르게 문제를 확인할 수 있는 기법이다[8]. 와이어 본딩 공정에서의 주요 기능 에 대한 내용과 주요 Parameter에 대해서 구성 요소 분석을 실시하였다[Table 3]. 캐필러리 의 궤적 형성에 따른 골드 와이어의 움직임과 관련하여 캐필러리의 동작을 프로세스 구 성도를 통하여 작성하였으며, 세부 항목에 대해서 유익 작용, 유해 작용, 약한 유익작용 으로 분류하였다[Fig. 4].

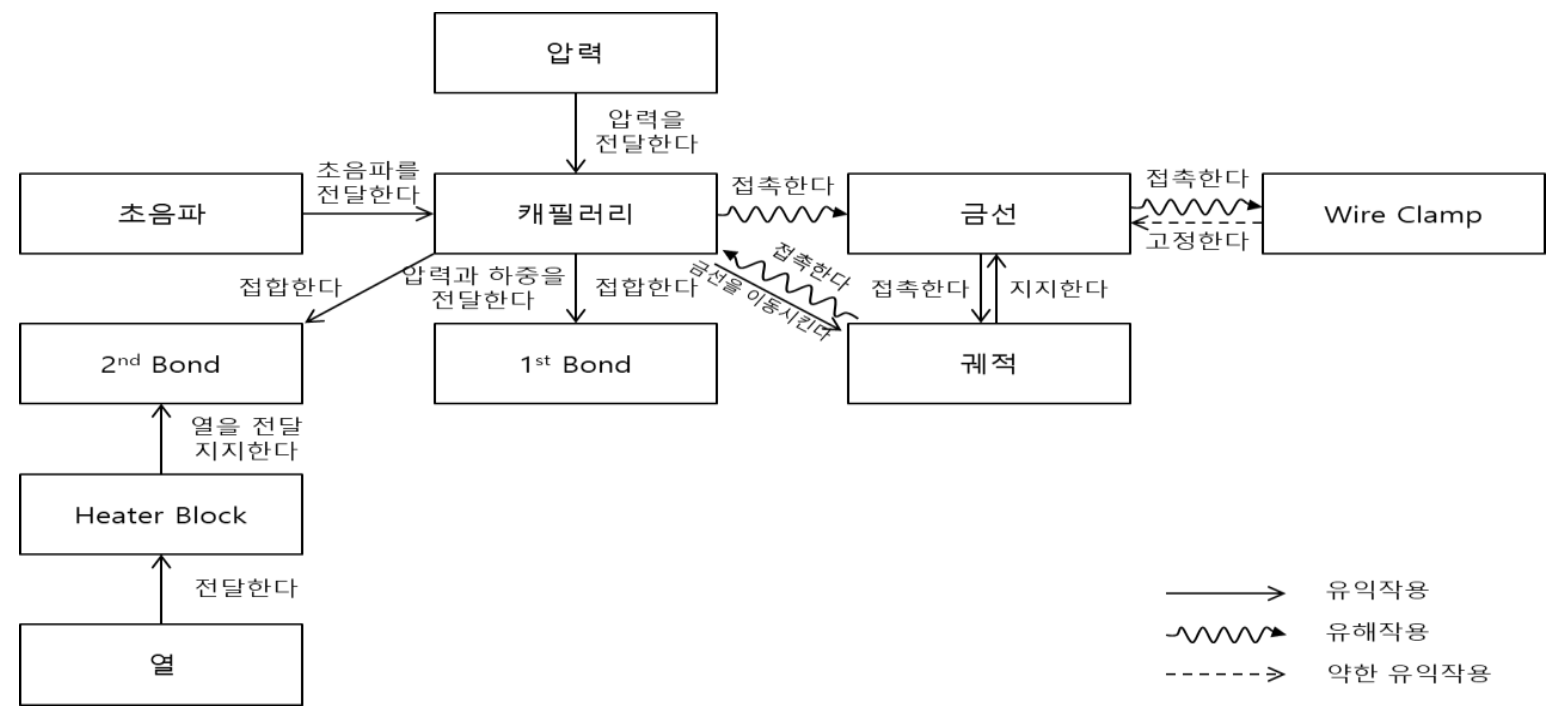


[그림 4] 상호 연관관계 분석

[Fig. 4] Correlation Analysis

\section{2 인과관계 분석 (Cause-Effect Chain Analysis: CECA 분석)}

골드 와이어를 반도체 $\mathrm{Pad}$ 와 기판에 결속하는 동작 시 골드 와이어 표면에 미세한 걸림 현상이 발생하여 BPT가 저하되는 문제를 해결하기 위하여 골드 와이어의 궤적 형성 시 많은 궤적을 형성하도록 하여 생산성이 저하되는 문제가 발생하였다. 골드 와이어의 궤적 형성 과정을 세밀하게 분석하기 위해 TRIZ 분석 도구인 인과관계 분석(Cause-effect chain analysis: CECA) 을 실시하였다. CECA 분석은 여러 가지 원인이 있는 문제를 체계적으로 분석하는 방법이다. 인과관계에 있어 유해한 작용이 발생하는 시간 Operation Time (OT)과 문제 발생 영역인 Operation Zone $(\mathrm{OZ})$ 을 분석하여 문제 해결방법에 더 쉽고 정확하게 도 와줄 수 있다[9]. 골드와이어의 궤적 형성과 관련된 첫 번째 Bonding과 두 번째 Bonding 사이에 골드 와이어의 높이를 유지하기 위해 추가된 궤적 형성에 의하여 골드 와이어의 높이는 안정적으로 유지가 되지만 많은 궤적으로 인하여 생산 속도가 저하되는 문제점을 확인할 수 있다[Fig. 5].

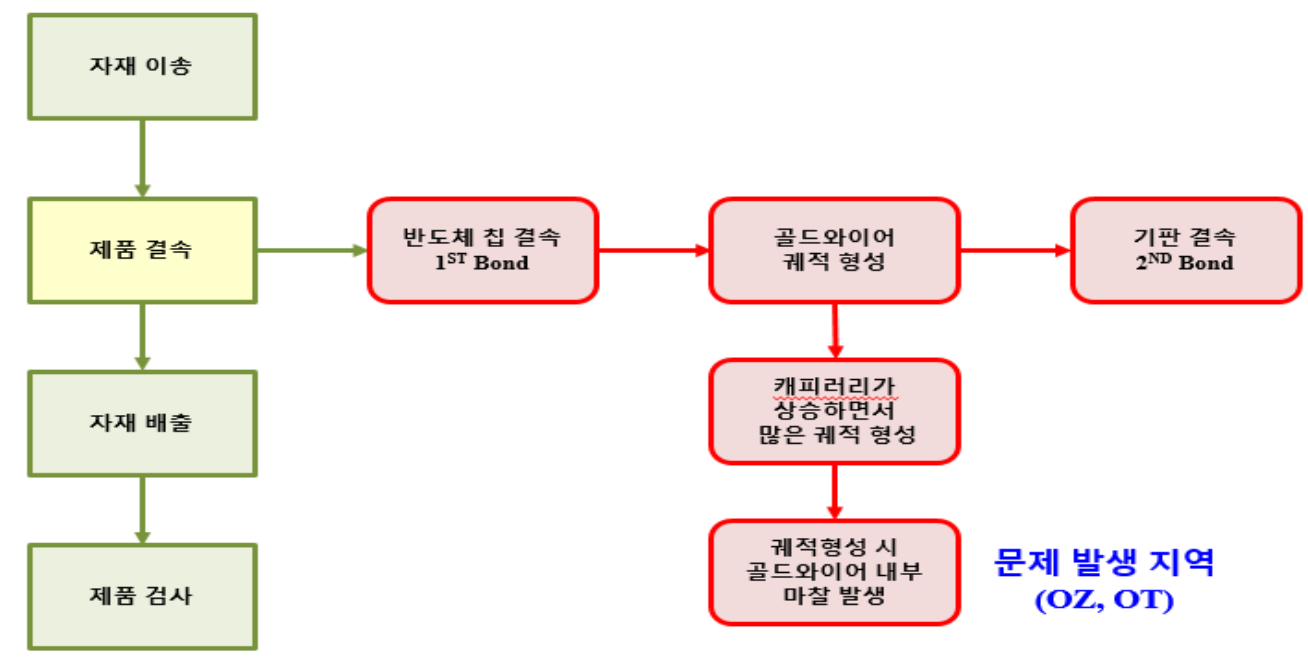

[그림 5] 인과관계 분석

[Fig. 5] Cause-Effect Chain Analysis

\section{3 작은 사람 모델 분석}

문제에 대해 깊이 있는 관점에서 확인하기 위해 작은 사람 모델 분석을 실시하였다. 작은 사람 모델 분석은 문제 대상의 일부가 된 것처럼 의인화하여 유추하는 방법이다[10]. 캐필러리가 골드 와이어의 궤적을 형성하는 과정에서 간섭되는 부위를 확인하였으며, 해당 부위는 캐필러리의 외경에 대한 Design과는 관계가 없음을 확인하였다. 실제 캐필러리의 Design의 확인 시 골드와이어의 궤적 형성과 관계되는 부위는 Inner Angle과 관련이 있음을 확인하였다[Fig. 6]. 


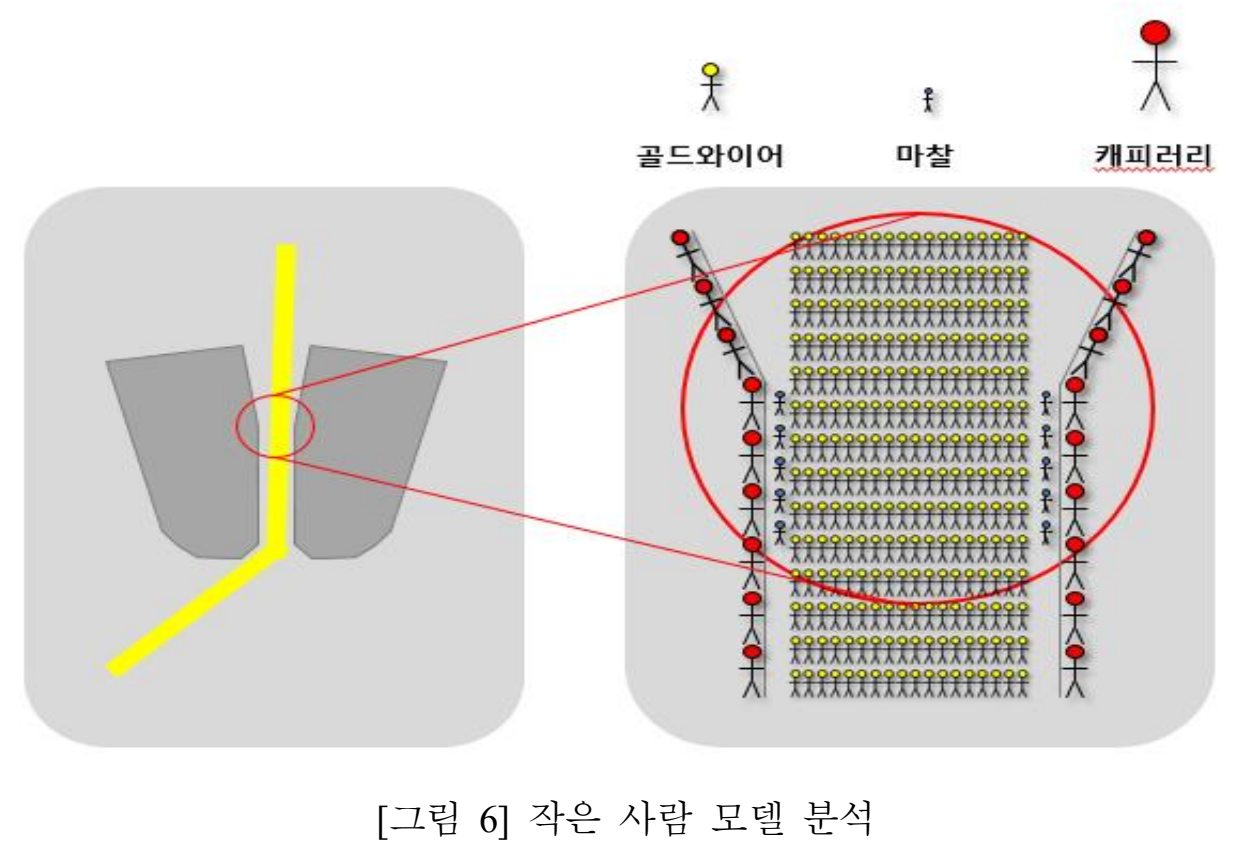

[Fig. 6] Little Man Model Analysis

\section{4. 문제 해결}

\section{1 이상적 해결안 제시}

본 논문에서는 40 가지 발명 원리, 물질 장을 이용한 표준해, 시간 및 공간을 분리하여 생각하는 분리 원리 등 각각의 기법을 적용하여 이상적인 해결안을 제시하였으며, 채택된 제시 안에 대해서 JUMP를 활용하여 Data 검증을 진행하였다. 이상적 최종 해결안 IFR은 “캐필러리는 많은 루프 궤적을 형성하면서도 캐필러리 내부에서 스스로 골드 와이어와의 내부마찰이 존재하지 않아야 한다.”라고 정의하였다.

\subsection{1 기술적 모순을 이용한 발명원리 아이디어}

기술적 모순이란 하나의 시스템에서 한가지 특성을 개선했을 때 다른 특성이 나빠지거나 새로운 문제가 발생하는 어려운 문제를 의미한다[11]. 현 상황의 기술적 모순은 궤적의 형성이 많으면 골드 와이어의 높이가 일정하게 유지되나 생산속도가 저하되고, 궤적의 형성이 적으면 골드 와이어의 높이가 일정하게 유지되지 않지만, 생산 속도가 증가하는 모순을 가지고 있다고 할 수 있다[Fig. 7]. 해당 모순을 40가지 발명 원리의 모순 행렬 표에 대입하여 세로축에 개선하는 특성을, 가로축에 악화하는 특성을 대입하여 확인한 결과 30 번 항목인 유연한 막 / 박막이라는 특성을 확인할 수 있었다. 이를 통한 개선 아이디어는 골드 와이어의 표면에 마찰이 발생하지 않도록 골드 와이어를 형성하면서 사용되는 신선 유를 증가 시켜 코팅을 진행하는 방안으로 마찰력을 감소하는 방안을 도출하였다[Table 4]. 
금선의 마찰이 많다 : 강한 : 생산 속도가 저하된다.

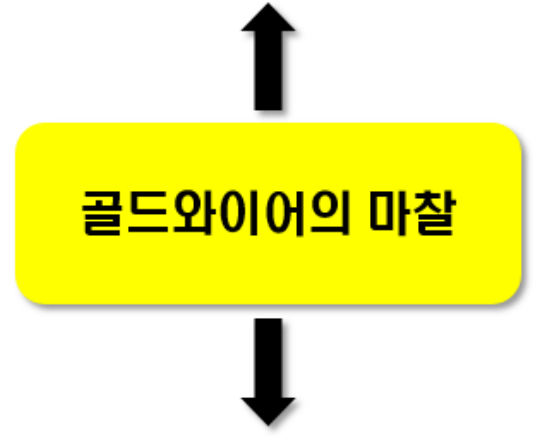

금선의 마찰이 적다 : 약한 : 생산 속도가 증가된다.

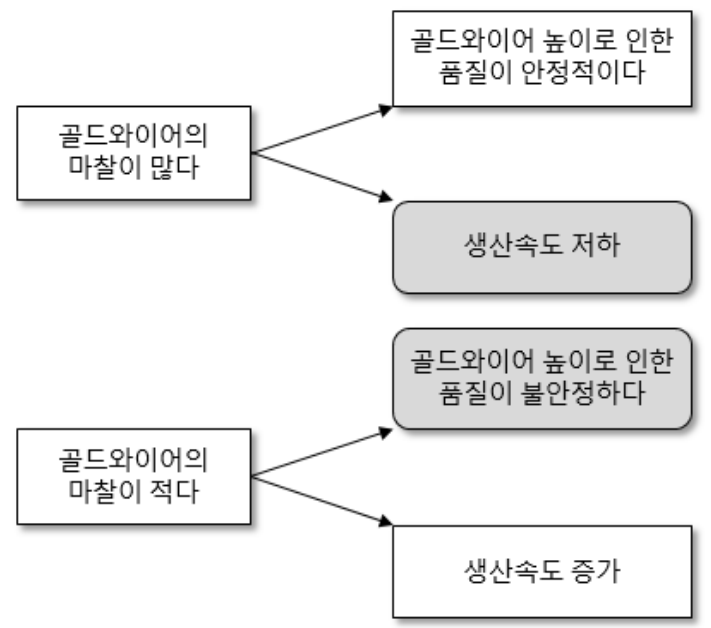

[그림 7] 기술적 모순

[Fig. 7] Technical Contradiction

[표 4] 발명원리

[Table 5] Invention Principle

\begin{tabular}{|c|c|c|}
\hline & $\begin{array}{c}\text { 악화하는 특성 } \\
\text { 5. 이동하는 물체의 면적 }\end{array}$ & 해결방법 \\
\hline $\begin{array}{c}\text { 개선하려는 특성 } \\
\text { 9. 속도 }\end{array}$ & 30. 유연한 막 / 박막 & $\begin{array}{c}\text { 표면에 마찰이 발생하지 않도록 골드와이어를 } \\
\text { 형성하면서 사용되는 신선 유를 증가 시켜 } \\
\text { 코팅을 진행하여 마찰력을 감소 }\end{array}$ \\
\hline
\end{tabular}

\subsection{2 물질-장 분석을 이용한 표준해}

TRIZ 이론에 따르면 어렵고 복잡한 모든 문제는 대부분 모순을 가지고 있으며, 이 모순은 발명원리와 분리원리를 가지고 창의적으로 해결할 수 있다고 할 수 있다. 그러나 모순을 가지고 있지 않거나, 혹은 모순을 찾기 어려운 상황에서는 TRIZ 문제 해결 Solution은 물질-장 분석을 시행하고 표준해를 통해 문제를 해결한다. 물질-장 분석은 두 물질과 그사이에 작용하는 장(Field)을 분석하여 유익한 관계와 유해한 관계, 그리고 부족한 관계를 찾는 분석기법이다. 그리고 문제 형태에 따라 물질을 효과적으로 도입하여 해결안을 찾을 수 있는 매우 체계적인 방법으로 현재의 문제는 물질-장 표준해를 활용한 문제해결 아이디어로 캐필러리 내부 공간의 분리를 통하여 골드 와이어 와의 마찰을 최소화하는 방안을 찾을 수 있었다[Fig. 8]. 

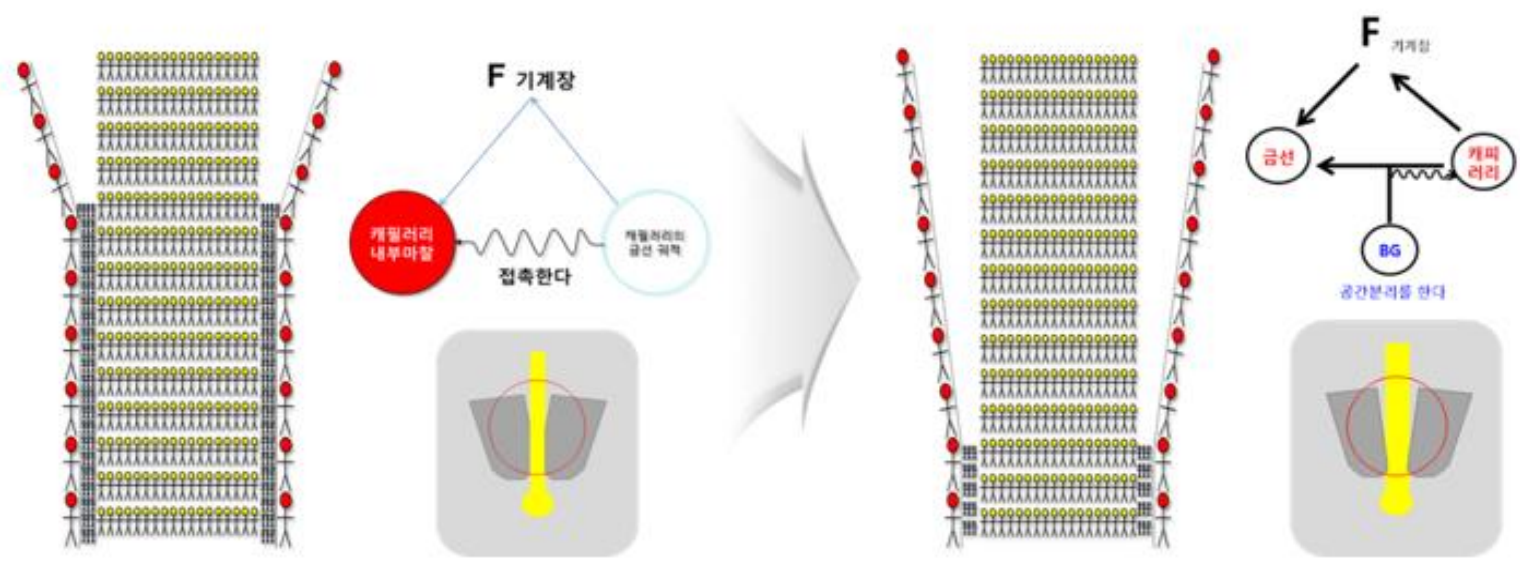

[그림 8] 표준해 물질-장 아이디어 도출

[Fig. 8] Standard Solution Material-field Idea

\section{2 최종 해결안 도출}

최종 해결안 도출을 위하여 IFR인 이상적 해결안과 모순 그리고 물질-장의 3 가지 분석을 통하여 캐필러리의 내부공간을 골드 와이어의 외부에 사용되는 신선 유를 통한 분리의 두 가지 아이디어를 확인하였으며, 이를 통한 검증을 토대로 문제를 해결해야 한다. 도출된 아이디어를 종합하여 최종 해결안 도출을 위한 평가를 진행하였다. 발명원리, 분리원리 그리고 IFR을 이용한 3 가지의 아이디어에 대한 평가를 진행하였다. 평가 결과 가장 경제적이고 적용 가능성이 높으며 다른 추가적인 문제를 최소화 할 수 있는 표준해의 아이디어인 “캐필러리의 내부의 지름을 넓혀 캐필러리 내부에서 발생하는 골드 와이어와의 마찰을 최소화한다"로 채택하였다[Fig. 9].

\begin{tabular}{|c|c|c|c|c|c|c|c|c|}
\hline \multirow{5}{*}{ ฮّ } & \multirow[b]{2}{*}{ No } & \multirow[b]{2}{*}{ 원리 } & \multirow[b]{2}{*}{ Idea 내용 } & \multicolumn{4}{|c|}{ Idea 평가( $: 5, \bigcirc: 3, \Delta: 1)$} & \multirow[b]{2}{*}{ 순위 } \\
\hline & & & & 비용 & $\begin{array}{l}\text { 유익 } \\
\text { 기능 } \\
\text { 증가 }\end{array}$ & $\begin{array}{l}\text { 적용 } \\
\text { 가능성 }\end{array}$ & 점수 & \\
\hline & 1 & IFR & $\begin{array}{l}\text { 캐필러리는 많은 루프궤적을 형성하면서도, 캐필러리의 } \\
\text { 내부에서 스스로 골드와이어와의 내부 마찰이 존재하지 } \\
\text { 않아야 한다. (궤적 형성 시 속도 향상). }\end{array}$ & $\mathrm{O}$ & 0 & $\triangle$ & 9 & 3 \\
\hline & 2 & 모순 & $\begin{array}{l}\text { 골드와이어의 표면에 마찰이 발생되지 않도록 골드와이 } \\
\text { 어의 표면을 신선유로 코팅을 진행한다. } \rightarrow \text { 마찰력 감소 }\end{array}$ & $\triangle$ & 0 & $\triangle$ & 11 & 2 \\
\hline & 3 & 표준해 & $\begin{array}{l}\text { 캐필러리 내부의 직경을 넚혀 캐필러리 내부에서 발생되 } \\
\text { 는 골드와이어와의 마찰을 최소화 한다. }\end{array}$ & $\mathrm{O}$ & 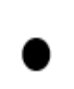 & 0 & 13 & 1 \\
\hline
\end{tabular}

[그림 9] 해결안 평가

[Fig. 9] Solution Evaluation 


\section{3 최종 해결안 평가}

최종 해결안인 캐필러리 내부의 지름을 넓혀 캐필러리 내부에서 발생하는 골드 와이어 와의 마찰을 최소화하기 위한 세부 아이디어를 통하여 캐필러리의 최적 내부 각도(Inner Angle)를 도출하기 위하여 추가적인 품질 평가를 진행하였다. 내부 산업보안 규정에 따라 내부각도는 각각 0 도, 7.5 도, 15 도, 20 도로 표현하였으며, 최적 내부각도 도출을 위한 평가 를 진행하였다. 해당 캐필러리의 내부 각도를 제외한 모든 Parameter를 비롯한 설비의 모 든 설정 상태는 같은 조건으로 평가를 진행하였다. (Power, Force, TEMP, Time 고정) 내부 각도에 따른 BST 점검 결과에 대하여 Tukey-Kramer 기법을 통해 평균적인 유의차를 분석 한 결과 모두 SPEC/Warning을 충족하는 수준인 것을 확인하였으며 내부 각도가 증가할수 록 BST가 증가함을 확인하였다[Fig. 10].

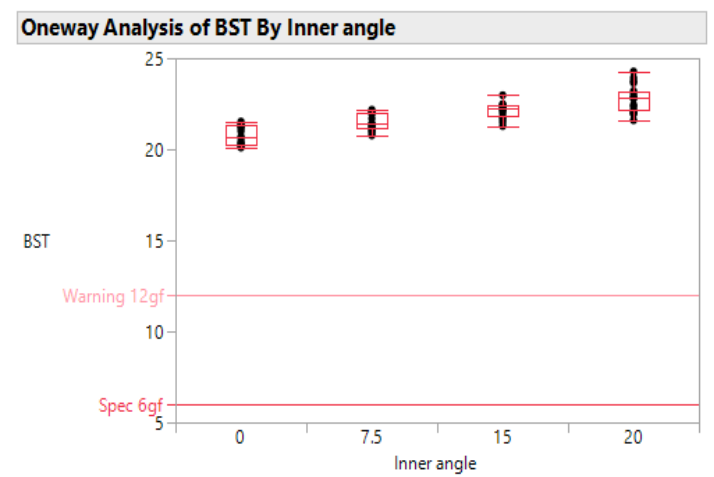

\section{Means Comparisons}

Comparisons for all pairs using Tukey-Kramer HSD

\begin{tabular}{|c|c|c|}
\hline \multicolumn{3}{|c|}{ Connecting Letters Rep } \\
\hline Level & & Mean \\
\hline 20 & A & 22.7671 \\
\hline 15 & B & 22.1689 \\
\hline 7.5 & C & 21.476 \\
\hline 0 & & 20.798 \\
\hline
\end{tabular}

Levels not connected by same letter are significantly different.

\section{[그림 10] BST 평가}

[Fig. 10] BST Evaluation

내부 각도에 따른 Ball size 점검 결과에 대하여 분석 결과 내부 각도가 증가함에 따라 Ball size가 증가하며, 정비례 $($ Rsquare $=0.89)$ 함을 확인하였다. Ball size의 경우 Bonding pad 의 크기인 $50 \mu \mathrm{m}$ 보다 작아야 하므로, 관계식을 통해 $\max$ 내부 각도를 도출하면 최대 8.57 도까지 사용이 가능한 것으로 확인되며 캐필러리 제작 공정 능력을 고려하면 8.5 도까지 사용 가능한 것을 확인하였다[Fig. 11].

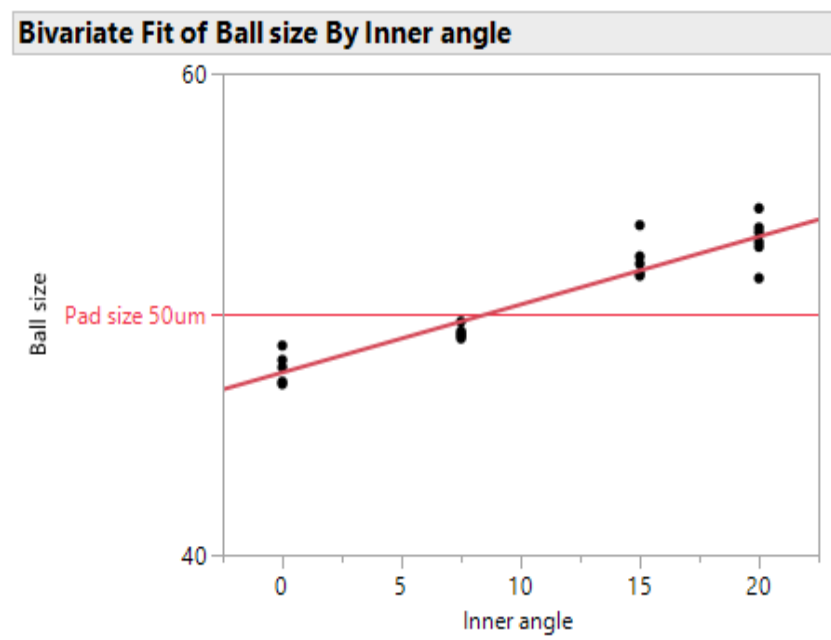

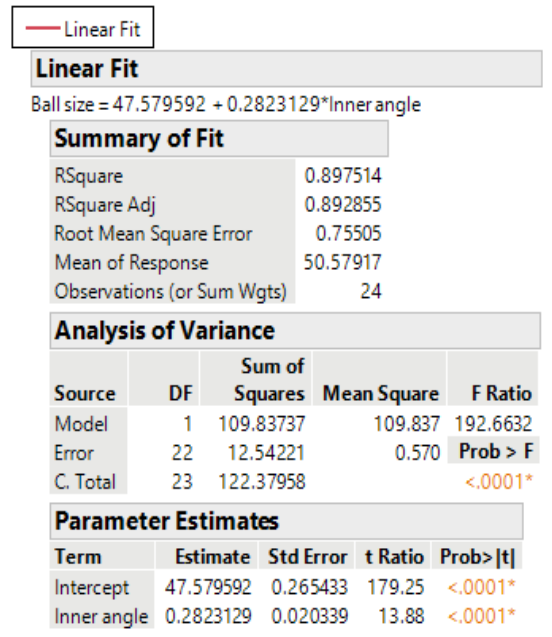


[그림 11] Ball Size 평가

[Fig. 11] Ball Size Evaluation

내부각도에 따른 $\mathrm{BPT}$ 점검 결과에 대하여 분석한 결과 내부 각도에 따라 BPT fail mode에 유의차가 있음을 카이 제곱 검정을 통해 확인하였다. 내부 각도가 0 도인 경우 Ball Neck Damage가 발생하여 BPT 진행 시 Ball Neck Broken이 $100 \%$ 수준으로 발생함을 확인할 수 있었고, 내부 각도가 7.5도 일 경우에는 Ball Neck Broken이 발생하지 않고 $\mathrm{BPT}$ 의 Hook 위치에서 Fail이 발생함을 알 수 있었다. 이를 통해 7.5도까지는 내부 각도의 증가가 Ball Neck의 Stress를 감소 시켜 주었음을 알 수 있었으며, 7.5도 이후로는 내부 각도의 증가가 다시 Ball Neck Stress를 유발하여 Ball Neck Broken을 발생시켰음을 알 수 있었다. 내부 각도의 변화는 골드 와이어의 표면에 실제 Damage를 발생시키지 않아도 Stress를 발생시키며 품질 저하를 가져올 수 있음을 확인하였다[Fig. 12]
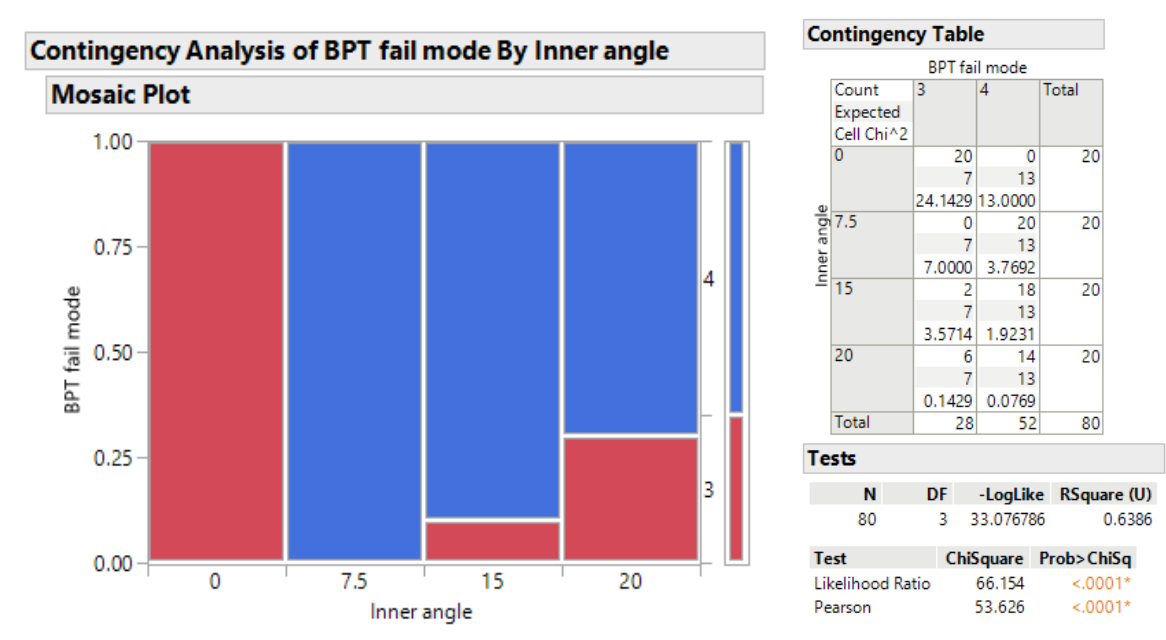

[그림12] BPT 평가

[Fig. 12] BPT Evaluation

캐필러리의 내부 접촉 각도에 따라서 Bond Ability가 변하는 것을 확인하였으며, 이 새로운 캐필러리의 내부 각도는 품질에 매우 중요한 요소로 작용하는 것을 확인하였다. 또한 설비의 Loop 궤적을 형성하는 부분에 접촉하는 골드 와이어와 캐필러리의 접촉면을 최소화하여 구현하므로 추가적인 Ball Neck Broken 등의 부수적인 품질에 대해서도 확보하는 결과를 이루게 되었다.

\section{5. 결론}

본 논문에서 반도체 Packaging 공정에서 발생하는 문제를 창의적 문제해결 이론인 트리 즈(TRIZ)를 이용해 해결하였다. 문제를 체계적으로 분석하여 와이어 본딩 공정의 캐필러 리(capillary)의 외부가 아닌 내부에서의 마찰이 있음을 확인하였고 내부 각도를 변경하여 와이어 본딩 품질을 확보할 수 있었다. 개선하고자 하는 접합력 향상은 Data 검증을 통하 여 신뢰성이 있음을 확인함에 와이어 본딩 공정 캐필러리 Design 변경을 통한 접합력 향 상과 생산성 향상이라는 결과를 달성하였다[Fig. 13]. 

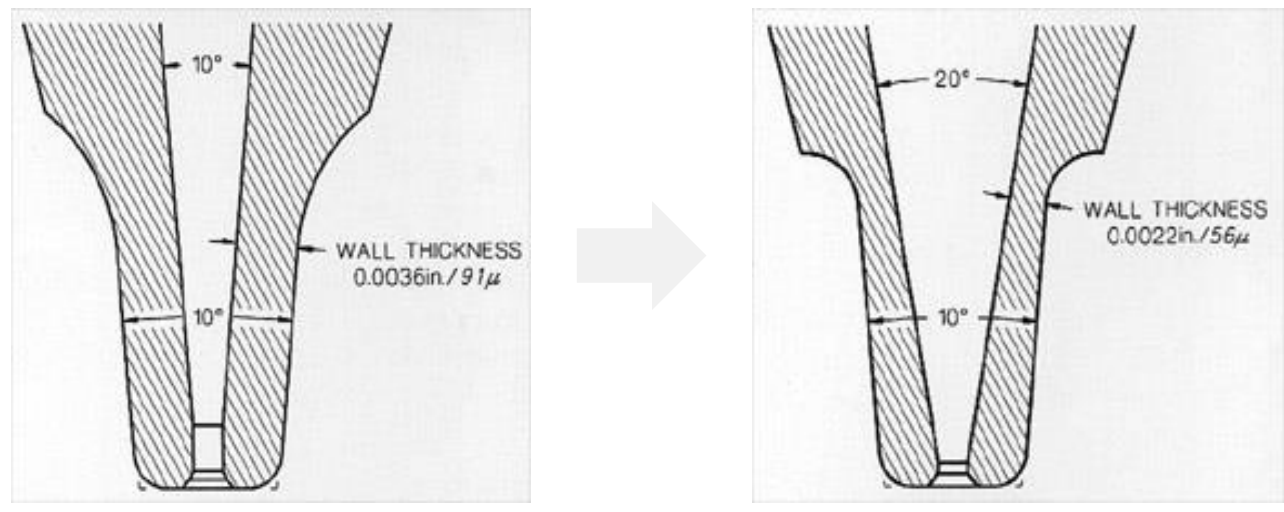

[그림13] 개선된 캐필러리 형상

[Fig. 13] Improved Capillary Shape

문제 해결을 위한 분석으로 거시적인 현상을 미시적으로 미시적인 현상을 마이크로 레벨 수준에서 작은 사람 모델로 접근하였다. 이와 같은 모든 산업군 특히 미세 공정의 생산 현장에서 발생하는 문제를 체계적으로 분석하여 다양한 해결안을 도출할 수 있는 창의적 문제 해결이론 TRIZ가 공정혁신의 유용한 도구임이 증명되었다.

\section{6. 감사의 글}

This research was supported by Basic Science Research Program through the National Research Foundation of Korea (NRF) funded by the Ministry of Education (2018R1D1A1B07049244).

\section{References}

[1] Kwanoo Ham, Kwang Soo Kim, A study on the improvement process according to the advancement of semiconductor devices: based on the case of the V-1 BAND improvement process, Korean Society for Quality Management Conference, (2018), May 25; Seoul, Korea. The-K Hotel Seoul Annex, pp.213-214.

[2] http://www.samsungsemiconstory.com/2206, Jan 16, (2020)

[3] Ae-sun Oh, Hyun-cheol Bae, Al wire bonding process in the power semiconductor package process, The Institute of Electronics Engineers of Korea academic conference, (2017), June 29 - July 1; Busan, Korea, pp. 229-231.

[4] Ae-sun Oh, Hyeon-cheol Bae, Yong-seong Um, Gwang-seong Choi, Ji-hye Son, Isle Jung, Bond Pull Test analysis using Al Ultrasonic Bonding process, The Institute of Electronics Engineers of Korea academic conference, (2016), June 22 -24; Jeju, Korea, pp.357-359.

[5] R. Chromik, D. Goldbaum, J. M. Shockley, Stephen Yue, E. Irissou, Jean-Gabriel Legoux, N. X. Randall, Modified ball bond shear test for determination of adhesion strength of cold spray splats, Surface and Coatings Technology, (2010), Vol.205, No.5, pp.1409-1414, DOI:10.1016/j.surfcoat.2010.07.037

[6] Heung-Yeol Na, Myung-Won Song, Young-Taek Park, On the Use of TRIZ Inventive Principles by Industries: Focusing on the Awarded Patents at the Korea Invention Patent Exhibition, Journal of Engineering Education Research, (2019), Vol.22, No.2, pp.28-35, DOI : 10.18108/jeer.2019.22.2.28

[7] E. K. Kim, B. C. Koo, A Study of Applying TRIZ in Software Development, Journal of the Korea Institute of Information and Communication Engineering, (2014), Vol.18, No.3, pp.719-726, https://doi.org/10.6109/jkiice.2014.18.3.719 
[8] Yong-won Song, Gyeong-mo Kim, Seong-hwan Kim, book Creative Problem Solving Theory TRIZ, KSA Media, (2017), pp.140-158.

[9] Yong-won Song, Gyeong-mo Kim, Seong-hwan Kim, book Creative Problem Solving Theory TRIZ, KSA Media, (2017), pp.236-244.

[10] Yong-won Song, Gyeong-mo Kim, Seong-hwan Kim, book Creative Problem Solving Theory TRIZ, KSA Media, (2017), pp.221-224.

[11] Taewoon Kim, Creative Problem Solving Process using TRIZ Contradiction Analysis, Journal of Engineering Education Research, (2015), Vol.18, No.3, pp.39-45, http://dx.doi.org/10.18108/jeer.2015.18.3.30 